\title{
Erratum to: Generic Programming
}

\author{
Jeremy Gibbons ${ }^{1}$ and Johan Jeuring ${ }^{2}$ \\ 1 University of Oxford, United Kingdom \\ ${ }^{2}$ Utrecht University, The Netherlands
}

\section{Erratum to: \\ J. Gibbons and J. Jeuring (Eds.) \\ Generic Programming DOI: $10.1007 / 978-0-387-35672-3$}

The book was inadvertently published with an incorrect name of the copyright holder. The name of the copyright holder for this book is: (c) IFIP International Federation for Information Processing. The book has been updated with the changes. 